\title{
Investigation of losses of infiltration by the basis of data on aerodynamic parameters of the building object
}

\author{
Dmitry Gribach, Julia Gribach", and Pavel Churin \\ Moscow State University of Civil Engineering, Yaroslavskoe shosse, 26, Moscow, 129337, Russia
}

\begin{abstract}
In the economy of the countries the problem of energy efficiency occupies one of the important places. The process of infiltration is one of the key aspects of energy efficiency in the construction industry. In turn, the process of infiltration is interconnected with climatic factors, such as wind. Existing norms and rules, which regulate construction activity, represent a calculation, the results of which give a large margin of reliability. However, because of this, a number of issues arise related to the economic and energy efficiency of construction projects. In this paper, a detailed description of the implementation of an experimental study of the wind effect on a building site is presented to reduce infiltration losses and increase the energy potential of the facility. The work contains the main results of this study, as well as a comparative analysis of the data obtained as a result of calculations based on approved standards.
\end{abstract}

\section{Introduction}

In the economy of the countries the problem of energy efficiency occupies one of the important places. Since the last century, the issue of saving energy resources and using them competently has been a priority in science $[1,2,3]$. One of the most affected industries in this area is construction. Since progress does not stand still: new materials are emerging, new technologies are being developed, and the regulatory framework must constantly evolve: documentation should be regularly monitored, adjustments and changes should be made if necessary, and irrelevant provisions, methods and calculation tolerances should be deleted.

\section{Review of existing studies}

One of the main aspects of the investigated problem is the process of infiltration. In the works of such researchers as Rymarov AG, Gagarin VG, Samarin OD, Kubenin AS, Pastushkov PP, Savichev VV, Vesnin VI, Kornienko S .V., the main materials related to the definition of the concept of energy efficiency, methods for assessing the effectiveness of energy resources, as well as the main links between the heat loss of the building and the

* Corresponding author: js-995@mail.ru 
difference in temperature of the internal and external air. So, for example, the article [4] is a graph of the distribution of energy costs, where $10 \%$ is allocated for heating the air during infiltration. Provided that changing the indicators of resources spent on other indicators is problematic (energy costs $(20 \%)$, heating of water $(10 \%)$, transmission losses $(30 \%)$, etc., engineers are faced with the task of minimizing heat costs in unorganized air exchange.

It is also necessary to note the problem of the lack of regulations on the regulation of air exchange in the territory of the Russian Federation [3,4,5]. The main problem for today is the lack of consideration for the quality of outdoor air, which requires regular airing. In order to achieve the goal of improving the quality of the indoor environment, it is necessary to ensure the necessary air exchange in the room, since air quality has a significant influence and the flow of infiltrating air.

To date, there is a large number of regulatory technical documents related to the regulation of energy efficiency of construction projects. However, these data require constant adjustment in the development of new technologies, design solutions and due to scientific progress in the use of secondary energy resources [6].

A detailed description of the approved methods for determining infiltration losses is presented in the article Gribach D., Gribach J., Churina P. "Influence of buildings aerodynamic characteristics on the calculation of infiltration loss results» [7]. To date, the definition of this indicator is possible on the basis of two documents: SP 50.13330.2016 and GOST R 55656-2013. The principal difference in calculating these methods is to simplify the procedure for determining the difference in external and internal air pressure $\Delta \mathrm{P}$ in SP 50.13330.2012 Thermal protection of buildings, thus the behavior of the distribution of the pressure difference over the surface of the building envelope $\Delta \mathrm{P}$ has lost an important property. At the same time, in GOST R 5565-2013 the value of $\Delta \mathrm{P}$ varies in height, but the figures for its calculation are taken according to the established standards, without reference to the particular case under consideration $[8,9]$.

Foreign norms also do not contain specific data on the calculation of infiltration losses, but experts in the field of DVT occupy the same position with Russian researchers: air leakage through enclosing structures leads to a significant percentage of energy loss. It should be emphasized that research in this area among colleagues from China $[10,11]$ is now deeper: the specialists of Tsinghua University received in the course of experimental studies the dependence of infiltration losses on the distribution of wind speed on the facades of buildings, the average annual and seasonal infiltration losses and determined the level of air pollution inside the room.

\section{Conducting of research}

Infiltration of air through the building envelope depends largely not only on the structural and planning features of the building, installed equipment, etc., but also on the environment, namely the climatic characteristics of the region in question, in particular - the effect of wind [12].

Determination of the flow rate of infiltration air through the air-permeable building element is possible in a third way: the data for calculation according to GOST R 556562013 can be obtained by performing experimental studies of the aerodynamic characteristics of a building object in the Large Research Gradient Wind Tunnel of the Moscow State University of Civil and Municipal Services (hereinafter - BIGAT NIU MGSU). Similar research is conducted on the basis of the Educational Scientific and Production Laboratory for aerodynamic and aero-acoustic testing of building structures. For this purpose, a technique for physical modeling of the wind impact on a building object was developed in the UNPL AAISK. The description of this technique is presented in the article [7]. Approbation of the presented technique is contained in this paper. 
The object of the study is Section No. $8 / 2$ of the residential complex located in the south-east of Moscow. The projected complex is a group of residential buildings. The height of the building is $50 \mathrm{~m}$ (fig. 1 ). The number of building is 15 floors.
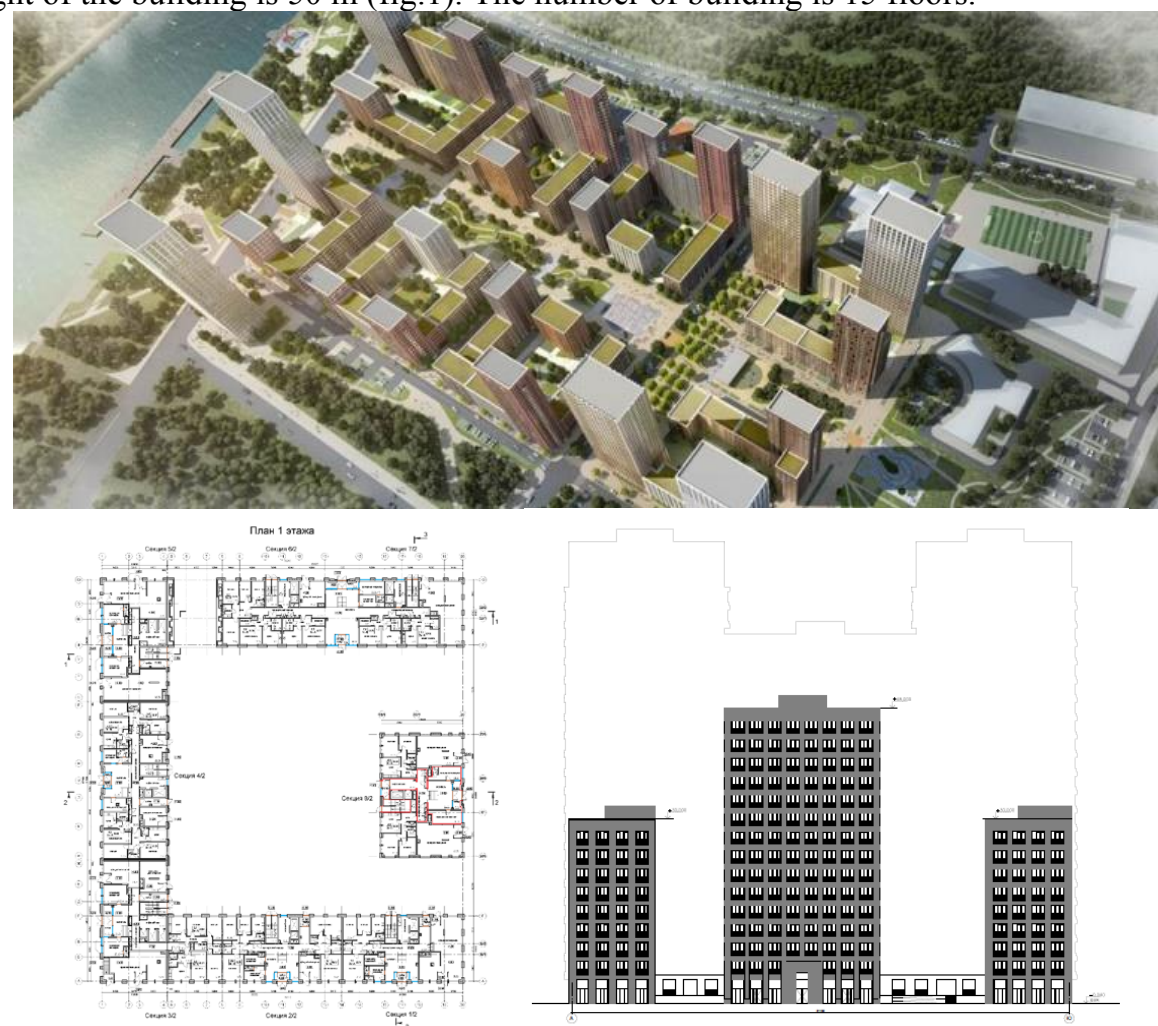

Fig. 1. Object of study

At the first stage, it is necessary to determine the calculated wind speeds and directions for experimental modeling. In accordance with JV 131.13330.2012 "Construction Climatology" the area under investigation belongs to the II-B building climatic region located in the center of the European part of Russia. The climate of the region is moderately continental, with a clearly expressed seasonality. The wind regime of the region is determined by the peculiarities of the circulation of the atmosphere. In winter, in the formation of the pressure field and the corresponding forms of atmospheric circulation, the Icelandic minimum and the Asian maximum play the main role, which determine the main directions of the wind. The average annual wind speed is $2.2 \mathrm{~m} / \mathrm{s}$ and has a distinct annual course. The highest average wind speeds are observed in the winter and reach a value of 2.4 $\mathrm{m} / \mathrm{s}$ in December. Minimum speeds are observed in the summer with an absolute minimum in July-September.

Further, a reduced model of the residential complex was developed and manufactured. The scale of the layout is 1: 250, the chosen scale satisfies the conditions of blocking the flow. The model is made of plexiglass $5 \mathrm{~mm}$ thick, the details of the mock-up were cut out on a specialized laser machine, and subsequently glued together with dichloroethane. After collecting all the components, the model installed on an automated rotary table in the working area of the BIGAT (fig. 2). The experiment was carried out at 8 angles of attack (from 0 to 315 ), the flow velocity in the working zone reached $12 \mathrm{~m} / \mathrm{s}$. 


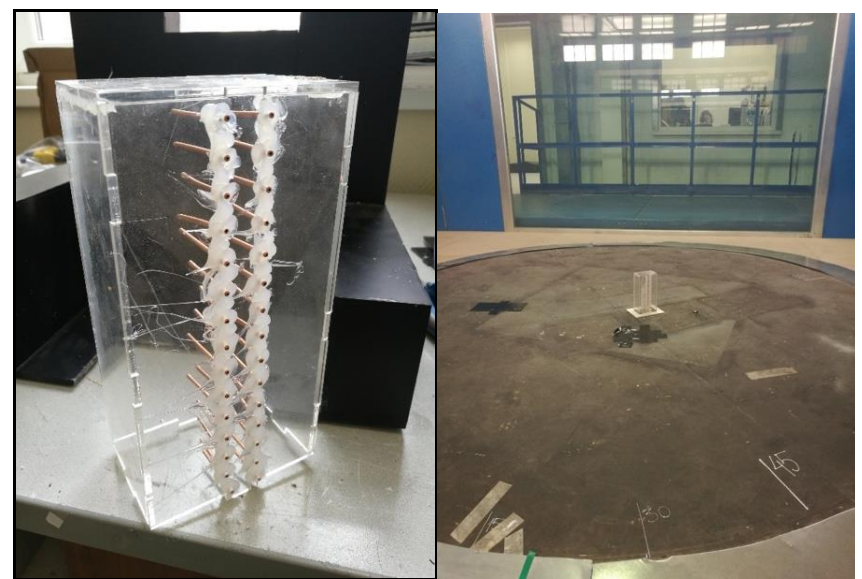

Fig. 2. Model with sensors, model in the working area of the BIGAT.

\section{Results of the research}

As a result of the experimental studies, the dimensionless aerodynamic coefficient $\mathrm{Cp}$ was obtained. Below is a table of values of the aerodynamic coefficients $\mathrm{Cp}$ throughout the building (table 1).

Table 1. Values of the aerodynamic coefficients $\mathrm{Cp}$.

\begin{tabular}{|c|c|c|c|c|c|c|c|c|}
\hline \multirow{2}{*}{$\begin{array}{c}\text { No } \\
\text { floor }\end{array}$} & \multicolumn{9}{|c|}{ Cp } \\
\cline { 2 - 9 } & 0 & 45 & 90 & 135 & 180 & 225 & 270 & 315 \\
\hline 1 & $-0,63$ & $-0,65$ & $-0,54$ & $-0,71$ & 0,16 & 0,83 & 0,76 & $-1,19$ \\
\hline 2 & 0,63 & 0,61 & 0,55 & $-1,15$ & $-0,51$ & $-0,65$ & $-0,47$ & $-0,87$ \\
\hline 3 & 0,63 & 0,62 & 0,59 & $-1,19$ & $-0,51$ & $-0,64$ & $-0,57$ & $-0,89$ \\
\hline 4 & 0,65 & 0,63 & 0,57 & $-1,18$ & $-0,53$ & $-0,67$ & $-0,50$ & $-0,94$ \\
\hline 5 & 0,69 & 0,68 & 0,60 & $-1,13$ & $-0,53$ & $-0,68$ & $-0,52$ & $-0,94$ \\
\hline 6 & 0,74 & 0,72 & 0,62 & $-1,10$ & $-0,56$ & $-0,70$ & $-0,55$ & $-0,95$ \\
\hline 7 & 0,79 & 0,77 & 0,65 & $-1,06$ & $-0,57$ & $-0,72$ & $-0,57$ & $-0,94$ \\
\hline 8 & 0,83 & 0,81 & 0,69 & $-1,04$ & $-0,59$ & $-0,73$ & $-0,57$ & $-0,93$ \\
\hline 9 & 0,86 & 0,85 & 0,73 & $-1,02$ & $-0,60$ & $-0,76$ & $-0,59$ & $-0,93$ \\
\hline 10 & 0,89 & 0,88 & 0,70 & $-1,01$ & $-0,62$ & $-0,79$ & $-0,61$ & $-0,94$ \\
\hline 11 & 0,91 & 0,90 & 0,75 & $-1,00$ & $-0,62$ & $-0,81$ & $-0,60$ & $-0,92$ \\
\hline 12 & 0,94 & 0,92 & 0,74 & $-0,99$ & $-0,61$ & $-0,79$ & $-0,59$ & $-0,94$ \\
\hline 13 & 0,91 & 0,89 & 0,70 & $-1,02$ & $-0,62$ & $-0,84$ & $-0,59$ & $-0,95$ \\
\hline 14 & 0.83 & 0,82 & 0,54 & $-1,02$ & $-0,61$ & $-0,87$ & $-0,56$ & $-1,00$ \\
\hline 15 & 0,66 & 0,65 & 0,44 & $-1,02$ & $-0,60$ & $-0,84$ & $-0,52$ & $-0,98$ \\
\hline
\end{tabular}

Further, in accordance with the approved algorithm, the flow rate of infiltration air is determined in accordance with GOST R 55656-2013. And the maximum is selected (table 2).

Table 2. The total value of Gi

\begin{tabular}{|c|c|c|c|c|c|c|c|}
\hline \multicolumn{7}{|c|}{ Gi } \\
\hline 0 & 45 & 90 & 135 & 180 & 225 & 270 & 315 \\
\hline 307,48 & 306,58 & 306,46 & 265,02 & 311,61 & 328,27 & 323,20 & 266,75 \\
\hline
\end{tabular}


Below is a graph of dates of the calculation of infiltration losses in accordance with GOST R 55656-2013 and GOST R 556-56-2013, taking into account the updated data (fig.3).

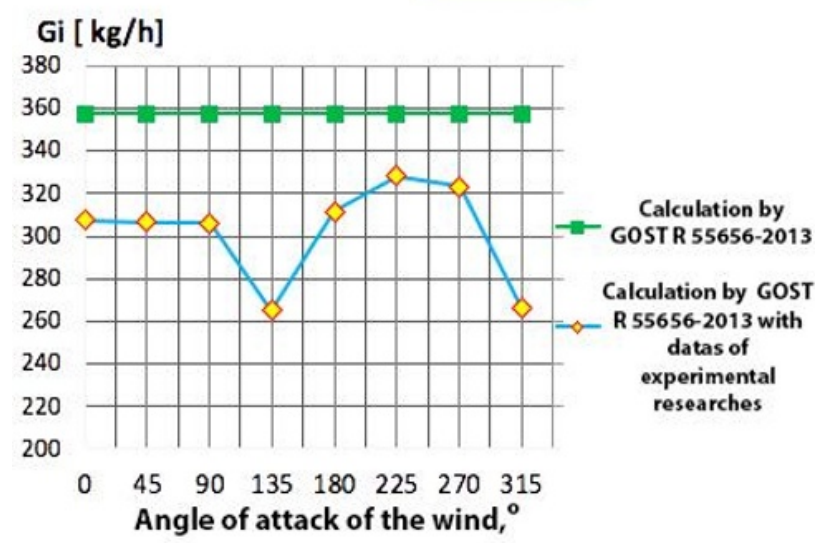

Fig. 3. The graph of dates of the calculation of infiltration losses.

On the basis of the above, it is possible to further refine the calculation results by using the values of the aerodynamic coefficients obtained during the experimental study. This option allows the most accurate use of aerodynamic characteristics of the building, namely: the shape of the building; the influence of the surrounding buildings; different directions of air flows along the wind rose. The value of infiltrating air is further reduced by $18-32 \%$, depending on the conditions of the experimental studies.

This work was financially supported by the Ministry of Education and Science (state task \#7.6075.2017/Bch). All tests were carried out using research equipment of The Head Regional Shared Research Facilities and Unique Scientific Installation Large Research Gradient Wind Tunnel of the Moscow State University of Civil Engineering.

\section{References}

1. ASHRAE Energy Standard 90.1-2007

2. ISO 52000-1:2017

3. E. Vakunin Izvest. Tul.GU 1 41-46 (2011)

4. O. Samarin Zhil. Str. 8 2-5 (2012)

5. A. Rymarov, V. Savichev Zhil. Str. 12 23-25 (2014)

6. E. Starostin, V.Skryabin Vest. S-VFU 53-57 (2007)

7. D. Gribach, J. Gribach, P. Churin MATEC Web Conf. 1965 (2018)

8. A. Kubenin Naukoved. 75 (2015)

9. D. Gribach, A. Kubenin, O. Poddaeva AISC 692 490-497 (2017)

10. P. Cheng, X. Li En. and Build. 164 219-225 (2018)

11. X. Cheng, H. Zhang, W. Pan and etc. Proc. Eng. 205 3954-3961 (2017)

12. Y. Pan, L. Li, C. Ma, N. Luo Ind. Const. 9031 (2014) 